\title{
ELABORAÇÃO DE BEBIDA COMPOSTA POR MISTURA DE GARAPA PARCIALMENTE CLARIFICADA-ESTABILIZADA E SUCOS DE FRUTAS ÁCIDAS ${ }^{1}$
}

\author{
Patricia PRATI ${ }^{2, *}$, Roberto Herminio MORETTI², Helena Maria André Bolini CARDELLO ${ }^{3}$
}

\begin{abstract}
RESUMO
O Brasil é grande produtor e consumidor de sucos de frutas, além de ser o maior produtor mundial de cana-de-açúcar. O caldo de cana, também conhecido popularmente como garapa, é uma bebida de grande aceitação pelo consumidor brasileiro, e nos vendedores ambulantes, normalmente é comercializada em misturas com sucos de frutas ácidas. O trabalho teve como objetivo avaliar fisicoquímica e sensorialmente as misturas de garapa parcialmente clarificada-estabilizada com sucos de limão, abacaxi e maracujá, e posteriormente eleger a bebida preferida do ponto de vista sensorial. Foram realizados Testes Sensoriais de Aceitação e de Intenção de Compra. As outras determinações foram $\mathrm{pH},{ }^{\circ} \mathrm{Brix}$, acidez, relação ${ }^{\circ} \mathrm{Brix} /$ Acidez, teor de ácido ascórbico, cor e turbidez. Os resultados das análises sensoriais indicaram que a mistura preferida foi aquela elaborada com garapa clarificada e 5\% de suco de maracujá, seguida da mistura que continha $10 \%$ de suco de abacaxi. No entanto, pelo Teste de Intenção de Compra a maioria dos consumidores afirmaram que "possivelmente compraria" todas as misturas avaliadas. Todos os produtos apresentaram boa retenção nos níveis de vitamina $\mathrm{C}$ após o tratamento térmico. Microbiologicamente todas as bebidas apresentaram-se adequadas para consumo.

Palavras-chave: cana-de-açúcar; sucos de frutas; análise sensorial.
\end{abstract}

\section{SUMMARY}

ELABORATION OF BEVERAGE COMPOSED BY BLENDS OF CLARIFIED-STABILIZED SUGAR CANE JUICE AND JUICE'S ACID FRUITS. Brazil is a great producer and consumer of fruit juices, in addition to being the World's largest producer of sugar cane. Sugar cane juice, popularly known as garapa, is a beverage highly appreciated by the Brazilian population and the street vendors usually sell it in mixtures with acid fruit juices. The objective of this study was the sensory and physical-chemical evaluation of partially clarifiedstabilized sugar cane juice in mixtures with lemon, pineapple and passion fruit juices, aimed at choosing the most appreciated beverage from the sensory point of view. The sensory analyses were those of acceptance and intention to buy and the remaining determinations carried out were $\mathrm{pH},{ }^{\circ} \mathrm{Brix}$, acidity, ratio, ascorbic acid content, color and turbidity. It was concluded from the sensory analyses that the prefered mixture was that formulated with clarified sugar cane juice and $5 \%$ passion fruit juice, followed by that containing $10 \%$ pineapple juice. However in the intention to buy test, the majority of the consumers affirmed that they would "possibly buy" all the mixtures evaluated. From the vitamin $\mathrm{C}$ results, it was concluded that all products showed a good retention of this constituent after the heat process. All the mixtures were in good microbiological condition for consumption.

Keywords: sugar cane; fruit juices; sensory evaluation.

\section{1 - INTRODUÇÃO}

O Brasil é o maior produtor mundial de cana-deaçúcar apresentando até agosto de 2002 uma produção de aproximadamente 360 mil toneladas. Os cinco maiores estados produtores são São Paulo, Paraná, Alagoas, Minas Gerais e Pernambuco [1].

O caldo de cana ou garapa, considerado um produto altamente nutritivo, de sabor agradável, e barato, é comercializado na rua, por vendedores ambulantes, que possuem moendas para extração. A maioria desses vendedores não possui instalações compativeis, assim como instrução adequada, que permita obtenção do produto em condições higiênico-sanitárias apropriadas [19].

A garapa, se estocada, necessita ser clarificada, pois minutos após a sua extração adquire coloração bastante escura devido à oxidação de seus componentes

1. Recebido para publicação em 05/01/2004. Aceito para publicação em 02/04/2005 (001273).

2 Departamento de Tecnologia de Alimentos, Faculdade de Engenharia de Alimentos - UNICAMP, Cidade Universitária "Zeferino Vaz", s/n, Campinas-SP, CEP 13083-970, CP 6121.E-mail:ppratio0@yahoo.com/E-mail: moretti@fea.unicamp.br

${ }^{3}$ Departamento de Alimentos e Nutrição, Faculdade de Engenharia de Alimentos - UNICAMP, Cidade Universitária "Zeferino Vaz", s/n, Campinas-SP, CEP 13083-970, CP 6121.E-mail: hellini@fea.unicamp.br

* A quem a correspondência deve ser enviada. (especialmente, clorofila e polifenóis). Tal fato pode influenciar negativamente o consumidor na aquisição desta bebida.

A clarificação do caldo de cana, realizada logo após a moagem, ocorre através da coagulação, floculação e precipitação dos colóides e substâncias corantes, eliminadas por posterior decantação e filtração, ou seja, forma-se um precipitado insolúvel que absorve e arrasta tais constituintes do caldo. A floculação pode ser obtida por uma mudança de $\mathrm{pH}$ do meio, utilizando-se reagentes químicos, e pelo aquecimento [12, 23].

No Brasil predominam dois modelos de clarificação: defecação simples (emprega apenas cal e aquecimento para obtenção de açúcar bruto), e sulfo-defecação (antes do tratamento com cal e aquecimento, ocorre adição de $\mathrm{SO}_{2}$ ao caldo para fabricação de açúcar cristal branco) [11].

Os agentes coagulantes, em geral, são sais de cátions trivalentes $\left(\mathrm{Al}^{+3}, \mathrm{Fe}^{+3}\right)$ cujo poder complexante é muitas vezes maior que o de cátions bi e monovalentes. Os flocos por eles formados apresentam grande superficie de adsorção de colóides e de material em suspensão [11].

Atualmente, tem-se testado um novo coagulante desenvolvido no Japão. Trata-se do Policloreto de Alumínio (PAC), que apresenta algumas vantagens em relação aos coagulantes normalmente empregados: pro- 
move floculação em qualquer faixa de pH; é mais eficiente que o sulfato de alumínio na remoção de colóides, com menor gasto de reagentes; gera menos resíduo de alumínio no produto final [11]. O fabricante recomenda 1000 ppm como dosagem máxima a ser adicionada.

Para que a coagulação ocorra é necessário que o meio esteja alcalino, o que é conseguido pela adição de agentes alcalinizantes tais como: óxido de cálcio (cal virgem), hidróxido de cálcio (cal hidratada), hidróxido de sódio ou carbonato de sódio. Tais reagentes quando adicionados ao caldo modificam o seu $\mathrm{pH}$, e aliados ao efeito da temperatura formam precipitados que removem as impurezas [11].

Atualmente, ainda não se tem estabelecido um $\mathrm{pH}$ ótimo para o processo de clarificação, mas sabe-se que a simples aplicação de cal (num caldo fresco) até alcançar um pH entre 7,5 e 8,5 produzirá uma clarificação satisfatória [20].

$\mathrm{O}$ aquecimento posterior do caldo tem por objetivo acelerar e facilitar a coagulação e floculação de colóides e elementos protéicos, emulsificar matérias graxas e ceras, ou seja, acelerar o processo de clarificação, aumentando a eficiência da decantação. A filtração, etapa posterior à decantação do caldo clarificado, é fundamental para a remoção não apenas de colóides, mas também de impurezas em suspensão [12].

A finalidade da clarificação do caldo de cana para consumo direto, não é obter um líquido límpido e sim turvo, porém com coloração amarelada. Nesta mudança de coloração, a clorofila é degradada através da acidificação do produto, empregando produtos químicos ou mesmo sucos de frutas ácidas. Quanto maior a quantidade de ácido adicionada, mais o produto perde a tonalidade verde tendendo então à tonalidade amarela.

Essa mudança baseia-se no fato de que a interação entre a clorofila e os ácidos presentes no meio resulta na perda do íon magnésio das clorofilas, o qual é então substituído por um dos prótons fornecidos pelos ácidos. No caso da garapa, esta substituição resulta na formação de uma coloração amarelada, enquanto que nas frutas e hortaliças há mudança da cor verde para verde-castanho [10].

A garapa pode ser considerada como um "suco de cana". Segundo LIMA [14], os sucos naturais geralmente são conservados por pasteurização e/ou adição de preservativos permitidos pela legislação.

Tal conservação se faz necessária, pois o suco é um produto perecível e os fatores físicos, químicos, e biológicos, responsáveis por suas alterações comprometem suas características químicas, físicas, organolépticas e nutricionais, influenciando a vida-de-prateleira do produto [9].

YUSOF, SHIAN \& OSMAN [25] citam que na Malásia, a garapa também é muito popular sendo considerada como uma bebida doce muito agradável ao paladar e que sacia a sede; sua comercialização no país se estende desde restaurantes simples de beira de estrada até restaurantes de hotéis de alta classe, fato que revela ser a produção de suco de cana um negócio muito lucrativo. Considerando-se sua importância tem-se procurado desenvolver processos que possam conservar a qualidade do produto fresco durante a estocagem do mesmo.

A adição de sucos ácidos ao caldo de cana (como já é comercializado nos "garapeiros") tem a intenção de melhorar sensorialmente a bebida, pois confere ao produto um sabor "resfrescante" muito agradável ao paladar já que promove uma mudança na relação ${ }^{\circ}$ Brix/Acidez do mesmo. Tem-se utilizado sucos de frutas ácidas como limão Tahiti, abacaxi Havai e atualmente maracujá-amarelo.

O Brasil é grande produtor e consumidor de sucos de frutas. O crescimento da produção industrial está ocorrendo principalmente devido ao surgimento de produtos que têm o suco como ingrediente secundário, ou seja, sorvetes, iogurtes, alimentos infantis etc.

Considerando que o Brasil é o maior produtor mundial de cana-de-açúcar e que nacionalmente a garapa é bastante apreciada, seria de grande interesse o desenvolvimento de tecnologias que promovessem a duração do produto por maior período de tempo, possibilitando sua melhor distribuição comercial.

Além disso, a obtenção de novos produtos seria uma forma de estimular o desenvolvimento de agroindústrias já existentes, bem como a implantação de outras microempresas do ramo, que poderiam melhorar o aproveitamento da infraestrutura disponível.

A pesquisa teve como objetivo estudar as características microbiológicas, físicas, químicas e sensoriais de misturas de garapa parcialmente clarificada-estabilizada e sucos de frutas ácidas como limão, abacaxi e maracujá, e posteriormente estabelecer qual a mistura preferida sob o ponto de vista sensorial.

\section{2 - MATERIAL E MÉTODOS}

\section{1 - MATERIAL}

\subsection{1 - Matéria-prima}

Foi utilizado caldo de cana-de-açúcar (Saccharum spp) da variedade RB72-454, comercializada para produção de garapa na região de Piracicaba.

Os sucos naturais utilizados nas formulações foram de: limão Tahiti (Citrus latifolia Tanaka), abacaxi Havai (Ananas comosus Cayenne) e maracujá-amarelo (Passiflora edulis f. flavicarpa).

\subsection{2 - Outros materiais}

O policloreto de alumínio (PAC) do tipo "Panclar P1010" foi o único agente químico de clarificação empregado no processo parcial de clarificação-estabilização do caldo, na concentração de 60ppm.

O ácido ascórbico foi utilizado como antioxidante, pois se trata de um antioxidante natural. A concentração de $125 \mathrm{ppm}$ foi estabelecida por PRATI, MORETTI \& CARDELLO [17]. Como conservador foi empregado o 
parabeno, pelas vantagens que apresenta $[7,8,13] \mathrm{e}$ em concentração também previamente estabelecida (40ppm).

No caso da garapa parcialmente clarificada-estabilizada adicionada de sucos de limão, abacaxi e maracujá, apesar das misturas serem submetidas ao tratamento térmico de pasteurização, foi também adicionado espessante de forma a evitar a separação de fases no produto final, por possivel atividade de enzimas pécticas presentes nos sucos. Em testes preliminares determinou-se como melhor agente espessante a Pectina Genu tipo 106 na proporção de 0,05\% (0,05g da pectina/ $100 \mathrm{~mL}$ da mistura).

As embalagens utilizadas foram do tipo PET (polietileno tereftalato) de capacidade de $500 \mathrm{~mL}$, incolores e transparentes, fornecidas gentilmente pela empresa Braspet localizada no município de Louveira, região de Campinas.

\section{2 - MÉTODOS}

\subsection{1 - Matéria-prima}

A extração do caldo de cana foi feita em moenda elétrica (Modelo STN-30 / 270 rpm) na Planta Piloto do Setor de Frutas, Hortaliças e Produtos Açucarados do Departamento de Tecnologia de Alimentos da Faculdade de Engenharia de Alimentos / UNICAMP.

Previamente à extração, os colmos tiveram sua casca removida manualmente com faca, e então foram sanitizados com solução contendo $10 \mathrm{ppm}$ de Cloro Ativo; após 10 minutos de contato da solução o material foi enxagüado com água corrente tratada. Da mesma forma procedeu-se a sanitização da moenda empregada nesta operação.

O caldo extraído foi parcialmente clarificado-estabilizado de acordo com procedimento estabelecido por PRATI \& MORETTI [16]: aquecimento em banho-maria $\left(65^{\circ} \mathrm{C} / 50 \mathrm{~min}\right)$, alcalinização com $\mathrm{Ca}(\mathrm{OH})_{2}$ até $\mathrm{pH} 8$, adição de $60 \mathrm{ppm}$ de policloreto de alumínio, decantação por 45 minutos, separação do sobrenadante com uso de bomba de vácuo (Modelo TE-058).

Os sucos naturais de limão, abacaxi e maracujá foram obtidos manualmente no Laboratório de Frutas, Hortaliças e Produtos Açucarados do Departamento de Tecnologia de Alimentos da FEA/UNICAMP.

As proporções de cada suco, empregadas na elaboração das misturas foram: $7,5 \%$ de suco de limão $(7,5 \mathrm{~mL}$ de suco de limão/100mL de garapa); 10\% de suco de abacaxi (10mL de suco de abacaxi/100mL de garapa); e 5\% de suco de maracujá ( $5 \mathrm{~mL}$ de suco de maracujá/ $100 \mathrm{~mL}$ de garapa). Tais proporções foram determinadas através de ensaios preliminares, tomando-se como critérios as quantidades que normalmente são adicionadas à garapa comercializada pelos vendedores ambulantes.

\subsection{2 - Produto processado}

O Fluxograma (Figura 1) ilustra as etapas do processamento das misturas.
Os produtos foram então submetidos a análises microbiológicas, físico-químicas e sensoriais descritas a seguir. As determinações físico-químicas foram submetidas à análise estatística aplicando o Teste de Tukey, através do pacote STATISTICA FOR WINDOWS [21].

- Análises microbiológicas: Contagem de Bolores e Leveduras, Contagem Padrão, e NMP para Coliformes Totais e Fecais, conforme a metodologia indicada pela APHA [24].

Garapa parcialmente clarificada-estabilizada

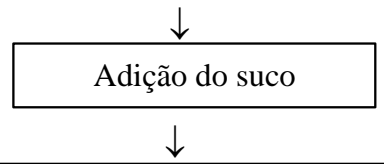

Acidificação (solução de ácido cítrico 10\%) até $\mathrm{pH}$ 4,0

$\downarrow$

Adição do espessante (0,05\% pectina genu tipo 106)

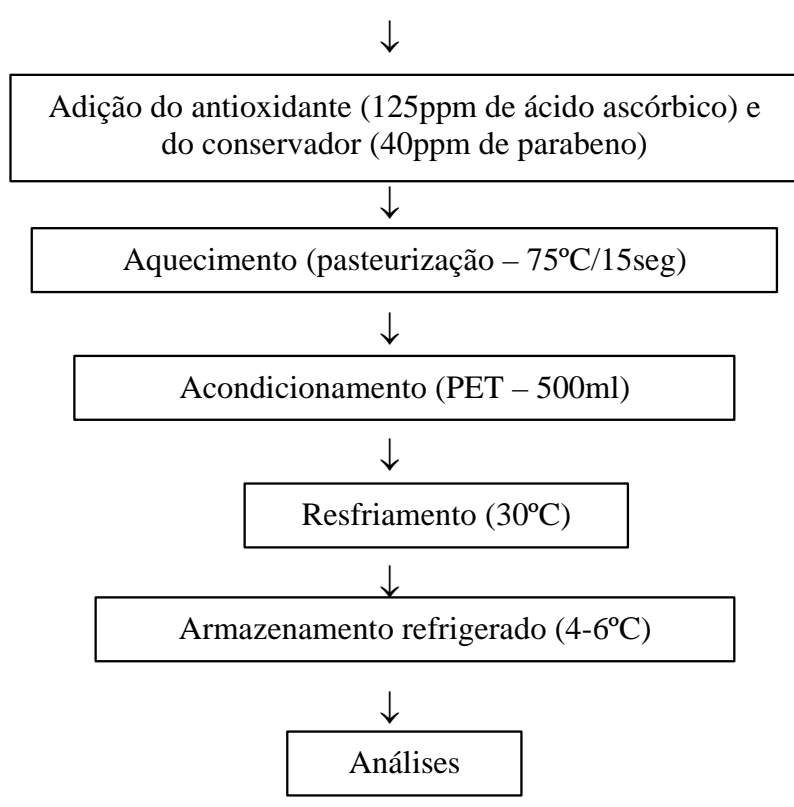

FIGURA 1. Etapas da obtenção de caldo de cana parcialmente clarificado-estabilizado adicionado de sucos de frutas ácidas.

- Determinações físico-químicas:

a) $\mathrm{pH}$ : segundo metodologia da ASSOCIATION OF OFFICIAL ANALITYCAL CHEMISTS [4];

b) teor de sólidos solúveis ( $\left.{ }^{\circ} \mathrm{Brix}\right)$ : segundo metodologia da ASSOCIATION OF OFFICIAL ANALITYCAL CHEMISTS [3];

c) acidez total titulável ou ATT (\% ácido cítrico): segundo metodologia da ASSOCIATION OF OFFICIAL ANALITYCAL CHEMISTS [3]; 
d) relação ${ }^{\circ}$ Brix / ATT;

e) teor de ácido ascórbico: segundo metodologia da ASSOCIATION OF OFFICIAL ANALITYCAL CHEMISTS [2] n.43046, modificada por BENASSI [5];

f) turbidez e cor instrumental (3 repetições/amostra): em espectrofotômetro para cor, modelo COLORQUEST II, marca Hunterlab. O aparelho foi calibrado para medição de Transmitância (TTRAN), no sistema de cor CIELAB (L*, $a^{*}$ e b*), iluminante $\mathrm{D}_{65}$ e ângulo do observador de $10^{\circ}$, empregando-se nas leituras cubeta com $10 \mathrm{~mm}$ de caminho ótico.

- Análise sensorial

Aplicou-se o Teste de Preferência usando escala hedônica não estruturada de 9 pontos (método afetivo). Os atributos avaliados foram: aparência, cor, aroma, sabor e impressão global do produto, com o objetivo de saber a preferência do produto junto ao mercado consumidor. Também aplicou-se o Teste de Atitude de Compra para cada produto analisado [15, 22].

Foram servidas quatro amostras: garapa parcialmente clarificada-estabilizada processada sem suco (testemunha / amostra 1), garapa parcialmente clarificadaestabilizada $+7,5 \%$ de suco de limão (amostra 2), garapa parcialmente clarificada-estabilizada $+10 \%$ de suco de abacaxi (amostra 3), garapa parcialmente clarificadaestabilizada $+5 \%$ de suco de maracujá (amostra 4 ).

A equipe sensorial foi composta por 35 provadores não treinados. As quatro amostras codificadas foram servidas em copos plásticos descartáveis, em volume padronizado de $50 \mathrm{~mL}$, em ambiente claro (mesa branca) e na forma de blocos completos casualizados, acompanhadas de biscoito água e um copo d'água, aplicando-se a ficha de avaliação apropriada.

Os resultados foram submetidos a Análise de Variância (ANOVA) e Teste de Média de Tukey $(p<0,05)$ [18]. Pela análise estatística dos resultados do Teste de Aceitação foi definida a mistura preferida testada sensorialmente.

\section{3 - RESULTADOS E DISCUSSÃO}

\section{1 - Análises microbiológicas}

Na Tabela 1 constam os resultados das determinações microbiológicas da garapa parcialmente clarificada-estabilizada processada sem e com sucos de limão, abacaxi e maracujá.

Para todas as misturas, a determinação de Coliformes Totais indicou números menores que $0,03 \mathrm{NMP} / \mathrm{mL}$ de produto, resultado este que se encontra dentro do padrão RDC $n^{\circ} 12$ [6] para caldo de cana pasteurizado, isolado ou em misturas, estabelecido como 10NMP/mL de produto.

A Contagem Padrão variou entre os valores de $10^{2} \mathrm{e}$ $10^{3} \mathrm{UFC} / \mathrm{mL}$ de produto. Já, a Contagem de Bolores e
Leveduras apresentou carga microbiana na ordem de $10^{1}$ e $10^{2} \mathrm{UFC} / \mathrm{mL}$ de produto. Tais valores indicam que os produtos não se encontram deteriorados.

TABELA 1. Análises microbiológicas da garapa parcialmente clarificada-estabilizada processada sem e com sucos de frutas ácidas.

\begin{tabular}{cccc}
\hline Produto & $\begin{array}{c}\text { Contagem } \\
\text { Padrão (UFC/mL) }\end{array}$ & $\begin{array}{c}\text { Contagem de Bolores e } \\
\text { Leveduras (UFC/mL) }\end{array}$ & $\begin{array}{c}\text { Coliformes Totais } \\
(\mathrm{NMP} / \mathrm{mL})\end{array}$ \\
\hline $\begin{array}{c}\text { Garapa clarificada } \\
\text { sem suco }\end{array}$ & $9 \times 10^{2}$ & $5 \times 10^{1}$ & $<0,03$ \\
$\begin{array}{c}\text { Garapa clarificada } \\
\text { com suco de limão }\end{array}$ & $9 \times 10^{2}$ & $8 \times 10^{1}$ & $<0,03$ \\
$\begin{array}{c}\text { Garapa clarificada } \\
\text { com suco de abacaxi } \\
\text { Garapa clarificada } \\
\text { com suco de } \\
\text { maracujá }\end{array}$ & $4 \times 10^{3}$ & $7 \times 10^{2}$ & $<0,03$ \\
* Ausência de Coliformes Fecais. & $3 \times 10^{2}$ & $<0,03$ \\
\end{tabular}

\section{2 - Determinações físico-químicas}

A Tabela 2 contém os resultados encontrados nas determinações físico-químicas da garapa parcialmente clarificada-estabilizada processada sem e com sucos naturais de limão, abacaxi e maracujá.

A mistura adicionada de suco de limão resultou no $\mathrm{pH}$ mais baixo, fato justificado pela alta acidez da bebida, diferindo então das outras amostras. Os demais produtos não apresentaram diferenças estatísticas em relação à acidez, mas sim quanto ao $\mathrm{pH}$.

Todas as amostras foram significativamente diferentes entre si, em termos do ${ }^{\circ}$ Brix, sendo que a bebida preparada somente com a garapa, ou seja, sem suco foi a que apresentou maior valor de sólidos solúveis.

A relação ${ }^{\circ}$ Brix/Acidez da bebida adicionada de suco de limão foi a menor, porque esta apresentou a maior acidez, diferindo estatisticamente das demais amostras. Para as outras misturas os valores desta relação não foram significativamente diferentes.

TABELA 2. Determinações físico-químicas da garapa parcialmente clarificada-estabilizada processada sem e com sucos de frutas ácidas *.

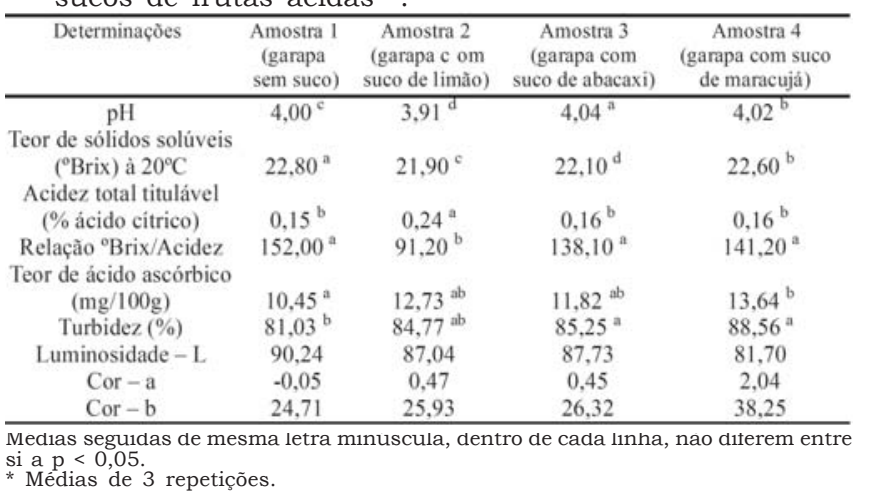

Em relação ao nível de ácido ascórbico somente as amostras 1 e 4 diferiram entre si de forma significativa. As perdas totais deste elemento após o processamento foram de $16,4 \%$ para a amostra 1 (passou de $12,5 \mathrm{mg}$ / $100 \mathrm{~mL}$ para $10,45 \mathrm{mg} / 100 \mathrm{~mL}$ ) e, de $5,4 \%$ para a amostra 
3 (passou de 12,5mg/100mL para $11,82 \mathrm{mg} / 100 \mathrm{~mL}$ ). Quanto aos demais produtos não ocorreram perdas devido a certa quantidade de vitamina C já presente nas matérias-primas (caldo de cana e sucos naturais).

As amostras com sucos apresentaram-se mais turvas (maior \% de turbidez) do que a garapa sem suco, devido ao teor de polpa. A bebida elaborada somente com garapa apresentou menor turbidez e foi estatisticamente diferente daquelas que continham suco de abacaxi e maracujá. A mistura contendo suco de limão não diferiu de nenhuma bebida analisada em termos da turbidez.

$\mathrm{Na}$ determinação de cor dos produtos, sabe-se que o valor L expressa a luminosidade ou claridade da amostra, e varia de 0 a 100; assim sendo, quanto mais próximo de 100, mais clara é a amostra e quanto mais distante, mais escura. Já, valores de a mais positivos indicam tendência à coloração vermelha e mais negativos, coloração verde. Valores de b mais positivos expressam maior intensidade de amarelo e mais negativos, maior intensidade de azul.

Sendo assim, observando os valores a e b é possível afirmar que a amostra com suco de maracujá tendeu às cores amarela e vermelha, e quanto ao valor L, a testemunha (garapa clarificada sem suco) apresentouse como a mais clara.

\section{3 - Análise sensorial}

A Figura 1 ilustra a atitude de compra dos consumidores em relação a cada produto analisado (garapa parcialmente clarificada-estabilizada processada sem suco - amostra 1; garapa parcialmente clarificada-estabilizada com suco de limão - amostra 2; garapa parcialmente clarificada-estabilizada com suco de abacaxi amostra 3; garapa parcialmente clarificada-estabilizada com suco de maracujá - amostra 4).

\section{Atitude de compra}

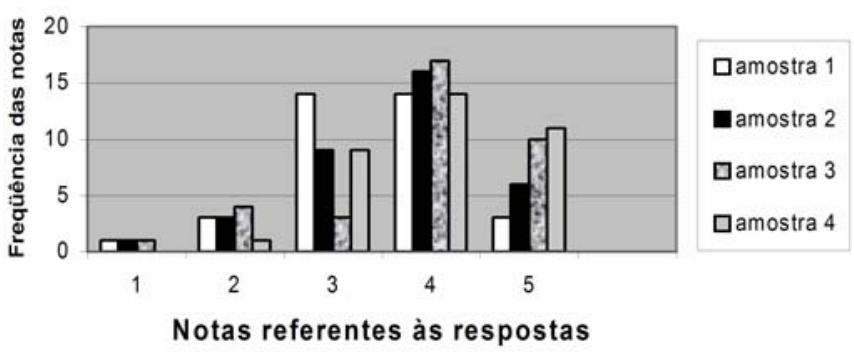

FIGURA 2. Teste de Intenção de Compra das amostras submetidas à análise sensorial (1-certamente não compraria; 2-possivelmente não compraria; 3-talvez comprasse/talvez não comprasse; 4-possivelmente compraria; 5certamente compraria).

A maior porcentagem das notas de atitude de compra atribuidas ficaram em "possivelmente compraria" mostrando que todas as bebidas teriam boa aceitação junto ao mercado consumidor. Cerca de $11 \%$ dos consumidores certamente comprariam o produto 4 (garapa clarificada-estabilizada $+5 \%$ suco de maracujá), $10 \%$ o produto 3 (garapa clarificada-estabilizada $+10 \%$ suco de abacaxi), $6 \%$ o produto 2 (garapa clarificada-estabilizada $+7,5 \%$ suco de limão), e $3 \%$ o produto 1 (garapa clarificada-estabilizada); 3\% dos consumidores certamente não comprariam os produtos 1, 2 e 3. A amostra 4 foi indicada como a preferida dentre as "formulações" analisadas, segundo o Teste de Atitude de Compra.

A Tabela 3 mostra as médias da notas dos atributos aparência, cor, aroma, sabor e impressão global, e a diferença estatística entre elas nos diferentes produtos.

Observa-se que para o atributo aparência não houve diferença significativa entre as amostras a $\mathrm{p}<0,05$.

Quanto aos atributos aroma e impressão global, as amostras 4 e 3 receberam maiores notas e não diferiram entre si mas sim de 2 e 1 a $p<0,05$, sendo que estas duas últimas também não diferiram entre si.

Para o atributo cor, a amostra 4 recebeu a maior nota e só diferiu de 2 , que recebeu a menor nota com relação a essa característica sensorial; 3 e 1 não diferiram entre si e nem das demais amostras.

Com relação ao atributo sabor, o produto 4 diferiu de 2 e 1 mas não de 3; 3 diferiu de 1 mas não de 2; 2 e 1 não diferiram entre si a $\mathrm{p}<0,05$.

TABELA 3. Valores médios dos atributos aparência, cor, aroma, sabor e impressão global das misturas (amostras)

\begin{tabular}{ccc}
\hline ATRIBUTO & AMOSTRA & MÉDIAS \\
\hline Aparência & 4 & $6.25^{\mathrm{a}}$ \\
& 3 & $5.98^{\mathrm{a}}$ \\
& 2 & $5.95^{\mathrm{a}}$ \\
& 1 & $5.90^{\mathrm{a}}$ \\
\hline Cor & 4 & $6.40^{\mathrm{a}}$ \\
& 3 & $5.93^{\mathrm{ab}}$ \\
& 1 & $5.86^{\mathrm{ab}}$ \\
\hline Aroma & 2 & $5.72^{\mathrm{b}}$ \\
\hline & 4 & $6.75^{\mathrm{a}}$ \\
& 3 & $6.48^{\mathrm{a}}$ \\
& 2 & $5.50^{\mathrm{b}}$ \\
Sabor & 1 & $4.91^{\mathrm{b}}$ \\
\hline Impressão global & 4 & $6.83^{\mathrm{a}}$ \\
& 3 & $6.66^{\mathrm{ab}}$ \\
& 2 & $5.88^{\mathrm{bc}}$ \\
& 1 & $5.39^{\mathrm{c}}$ \\
\hline${ }^{\mathrm{p}}$ médias seguidas de mesma letra (dentro de cada atributo), não diferem entre si a & $6.82^{\mathrm{a}}$ \\
& 4 & $6.63^{\mathrm{a}}$ \\
& 3 & $5.83^{\mathrm{b}}$ \\
& 2 & $5.60^{\mathrm{b}}$ \\
\hline
\end{tabular}

Em todos os casos, apesar de em alguns deles não haver diferença significativa entre as médias das notas, podemos observar que a ordenação das amostras da maior para a menor nota foi $4>3>2>1$, mostrando uma certa tendência em se eleger a "formulação" 4 como a preferida.

Como os atributos sensoriais mais relevantes para a pesquisa foram cor, sabor e impressão global, considerou-se somente os resultados das análises desses três atributos, ou seja: a amostra 4 (maior nota) diferiu significativamente de 2 a $\mathrm{p}<0,05$ em relação a tais atributos, e só não diferiu de 1 quanto à cor; 3 não 
diferiu de 4 em nenhuma das situações, e também não diferiu de 1 e 2 em relação à cor, porém diferiu de 1 quanto aos outros dois atributos, sendo que em relação ao sabor não diferiu de 2 , mas sim quanto à impressão global.

\section{4 - CONCLUSÕES}

As variações das características físico-químicas ocorridas entre as diferentes misturas de garapa processada e os sucos naturais citados, já eram esperadas. Todos os produtos apresentaram boa retenção de vitamina $\mathrm{C}$ (baixo índice de perda) após o processamento térmico.

Nas condições da pesquisa em questão, as determinações microbiológicas indicaram boas condições fitossanitárias de processamento das bebidas, que portanto se apresentavam adequadas ao consumo.

Considerando os resultados do Teste de Aceitação e do Teste de Atitude de Compra elegeu-se a amostra 4 (garapa parcialmente clarificada-estabilizada $+5 \%$ de suco de maracujá) como o produto preferido em termos de características sensoriais, seguido das amostras 3 (garapa parcialmente clarificada-estabilizada $+10 \%$ de suco de abacaxi), 2 (garapa parcialmente clarificadaestabilizada $+7,5 \%$ de suco de limão) e 1 (somente garapa parcialmente clarificada-estabilizada acidificada com solução 10\% de ácido cítrico).

\section{5 - REFERÊNCIAS BIBLIOGRÁFICAS}

[1] AGRIAnUal. Anuário da Agricultura Brasileira. São Paulo: Argos/FNP Consultoria e comércio, 2003.

[2] ASSOCIATION OF OFFICIAL ANALYTICAL CHEMISTS. Official methods of analysis of A.O.A.C. Internacional. 12.ed. Washington, 1984. p.844-845.

[3] ASSOCIATION OF OFFICIAL ANALITYCAL CHEMISTS. Official methods of analysis of A.O.A.C. Internacional. 16ed. v. II, cap.37, 1997a: Fruits and fruit products.

[4] ASSOCIATION OF OFFICIAL ANALITYCAL CHEMISTS. Official Methods of Analysis of A.O.A.C. Internacional. 16ed. v. II, cap.42, 1997b: Vegetable products, processed.

[5] BENASSI, M.T. Análise dos efeitos de diferentes parâmetros na estabilidade de vitamina $\mathrm{C}$ em vegetais processados. Campinas, 1990 159p. Dissertação (Mestrado) - Faculdade de Engenharia de Alimentos/ UNICAMP.

[6] BRASIL. Ministério da Saúde. Agência Nacional de Vigilância Sanitária. Resolução RDC n 12, 2 jan. 2001. Diário Oficial, Brasília, 2001. Seção I, alínea 17i.

[7] FRANCO, B.D.G.M.; LANDGRAF, M. Microbiologia dos Alimentos. São Paulo: Atheneu, 1996. 182p.

[8] GAVA, A.J. Emprego de conservadores químicos em alimentos. Boletim da Sociedade Brasileira de Ciência e Tecnologia de Alimentos, v.13, n.3, p.183-194, jul./ set. 1984.

[9] GRAUMLICH, T.R.; MARCY, J.E.; ADAMS, J.P. Asseptically packaged orange juice and concentrate: a review of the influence of processing and packaging conditions on quality. Journal of Agricultural and Food Chemistry, v.34, n.3, p. 402-405, 1986.

[10] IADEROZA, M.; DRAETTA, I.S. Ênzimos e Pigmentos - influências e alterações durante o processamento. In: SOLER, M.P. Industrialização de frutas. 2.ed. Campinas: Instituto de Tecnologia de Alimentos, 1991. cap.2, p.17-31. (Manual Técnico, 8).

[11] KOBLITZ, M.G.B. Estudo de método para remoção de polissacarideos que precipitam em cachaça. Campinas, 1998. 85p. Dissertação (Mestrado) - Faculdade de Engenharia de Alimentos/UNICAMP.

[12] KOBlitz, M.G.B.; MORETTI, R.H. Polysaccharide removal from refined sugar syrup. Internacional Sugar Journal, v.101, n.1206, p.323-325, 1999.

[13] LEITÃO, M.F.F. Microbiologia de sucos e produtos ácidos. Boletim do Instituto de Tecnologia de Alimentos, n.33, p.9-42, mar 1973.

[14] LIMA, U.A.L. Agroindustrialização de frutas. São Paulo: FEALQ, 1998. 151p.

[15] MeilgaARD, M.; CIVILle, G.V.; CARR, B.T. Sensory Evaluation Techniques. New YorK: CRC Press, 1987. $281 \mathrm{p}$.

[16] PRATI, P.; MORETTI, R.H. Desenvolvimento de processo para clarificação de caldo de cana para consumo. Anais - XVIII Congresso Brasileiro de Ciência e Tecnologia de Alimentos. Porto Alegre, 2002.

[17] PRATI, P.; MORETTI, R.H.; CARDELLO, H.M. Estudo de três diferentes concentrações de ácido ascórbico na qualidade sensorial de garapa clarificada estocada sob refrigeração. Anais - IV Brazilian Meeting on Chemistry of Food and Beverages. Campinas, 2002.

[18] SAS Institute. SAS User's Guide: statistics. Cary, USA: SAS Inst., 1993.

[19] SOCCOL, C.R.; SCHWAB, A.; KATAOKA, C.E. Avaliação microbiológica do caldo de cana (garapa) na cidade de Curitiba. Boletim do Centro de Pesquisa e Processamento de Alimentos, v.8, n.2, p.116-125, jul./ dez. 1990.

[20] SOUZA, J. Estudo da eficiência de alguns polieletrólitos utilizados na clarificação do caldo de cana. Piracicaba, 1988. 101p. Dissertação (Mestrado) - Escola Superior de Agricultura "Luiz de Queiroz"/USP.

[21] STATISTICA FOR WINDOWS. Copyright ${ }^{O}$ StaSoft. Inc., Tulsa. Version 5.0. 1995.

[22] STONE, H.; SIDEL, J.L. Sensory Evaluation Practices. New York: Academic Press, 1993. 338p.

[23] STUPIELlo, J.P. Cana de Açúcar: cultivo e utilização. Campinas: Fundação Cargil, 1987. v.II., p.761-804: A cana-de-açúcar como matéria-prima.

[24] VAndersant, C.; SPlitstoesser, F.O. Compendium of methods for the microbiological examination of foods. $3^{\text {th }}$ ed. Washington, D.C.: American Health Association (APHA), 1992. 1219p.

[25] YUSOF, S.; SHIAN, L.S.; OSMAN, A. Changes in quality of sugar-cane juice upon delayed extration and storage. Food Chemistry, v.68, p.395-401, 2000.

\section{6 - AGRADECIMENTOS}

Ao Conselho Nacional de Desenvolvimento Cientifico e Tecnológico (CNPq) e à Fundação de Amparo à Pesquisa do Estado de São Paulo (FAPESP) pelo apoio técnico, científico e financeiro oferecidos para a realização da pesquisa em questão. 